\title{
Effect of the Escherichia coli EMO strain on experimental infection by Salmonella enterica serovar Typhimurium in gnotobiotic mice
}

J.V.M. Lima-Filho' ${ }^{1}$, L.Q. Vieira ${ }^{3}$, R.M.E. Arantes ${ }^{4}$ and J.R. Nicoli ${ }^{2}$

\author{
'Departamento de Biologia, Universidade Federal Rural de Pernambuco, \\ Recife, PE, Brasil \\ Departamentos de ${ }^{2}$ Microbiologia, ${ }^{3}$ Bioquímica-Imunologia and \\ ${ }^{4}$ Patologia Geral, Instituto de Ciências Biológicas, \\ Universidade Federal de Minas Gerais, Belo Horizonte, MG, Brasil
}

\section{Correspondence \\ J.R. Nicoli \\ Departamento de Microbiologia ICB, UFMG \\ Caixa Postal 486 \\ 30161-970 Belo Horizonte, MG Brasil \\ Fax: +55-31-3499-2733 \\ E-mail: jnicoli@icb.ufmg.br \\ Research supported by FAPEMIG (CBB 1413/98) and CNPq (No. 479451/01-0). J.V.M. Lima-Filho, L.Q. Vieira and J.R. Nicoli are recipients of CNPq fellowships. \\ Part of a Ph.D. thesis presented by J.V.M. Lima-Filho to the Departamento de Microbiologia, ICB, UFMG, Belo Horizonte, MG, Brazil.}

Received May 8, 2003 Accepted April 7, 2004

\begin{abstract}
An experimental infection with Salmonella enterica subsp. enterica serovar Typhimurium was evaluated in gnotobiotic mice previously exposed to a plasmid-free non-pathogenic Escherichia coli (EMO strain). Mice were exposed to EMO (experimental) or not (control) 10 days before challenge with Salmonella Typhimurium $\left(10^{2}\right.$ colony forming units (CFU)/mouse). Survival after challenge was higher $(\mathrm{P}<0.05)$ in the experimental group $(16 \%)$ than in the control animals $(0 \%)$. Histopathological examination of the colon and ileum mucosa of the experimental group showed less extensive lesions such as edema, cell inflammatory infiltration and hyperemia. The epithelial cells of the mucosal surface and the production of the mucous layer were also better preserved in the experimental group. The population levels of Salmonella Typhimurium in the feces were initially 10 -fold lower $(\mathrm{P}<0.05)$ in the experimental groups. However, 3 days after challenge both experimental and control groups showed similar population levels ranging from $10^{8}$ to $10^{9} \mathrm{CFU} / \mathrm{g}$ of feces. The intestinal contents of total and antiSalmonella Typhimurium sIgA were higher in the experimental groups 10 days after inoculation of E. coli EMO strain. Translocation of Salmonella Typhimurium to the spleen was 10 -fold lower (P $<0.05$ ) in the experimental group only on day 3 after infection. This was not related to an increase in the bacterial blood clearance of the animals, as shown by experimental venous challenge with $E$. coli B41. In conclusion, treatment of mice with E. coli EMO strain promoted a relative protection against experimental infection with Salmonella Typhimurium. This protection was not due to the reduction of the population of pathogens in the intestine but was probably related to stimulation of the immune response.
\end{abstract}

Key words - Probiotic - Salmonella - Escherichia coli - Gnotobiotic mice 


\section{Introduction}

Control and treatment of infectious diseases frequently are challenged by the development of antibiotic resistance, increased frequency of opportunistic infections in immunocompromised patients, and the emergence of new types of pathogens. These factors, as well as inappropriate therapy, result in an increased exposure of the population to antibiotics, which, in turn, select resistant pathogenic strains. The World Health Organization (WHO) held a conference (1) to discuss this increase in antibiotic resistance, which today is "a major public health problem in both developed and developing countries throughout the world". With this in mind, the WHO recommends global programs to reduce the use of antibiotics and increased efforts to prevent disease through the development of newer, more effective and safer therapies.

Microorganisms that have been used to achieve this goal have been called probiotics. Several species of lactic acid-producing bacteria (Lactobacillus, Bifidobacterium, Streptococcus) and yeast (Saccharomyces) constitute a significant proportion of the biotherapeutic agents studied in the world (2). Probiotics are microorganisms mainly isolated from the intestines of healthy humans which are thought to protect the host against infections by at least four mechanisms: a) antagonism against pathogenic microorganisms through the production of inhibitory compounds (3); b) competition with the pathogen for adhesion sites or nutritional sources (4); c) inhibition of the production or action of bacterial toxins $(5,6)$, and d) immunomodulation (7). The likely contribution of each of these mechanisms is difficult to determine in the presence of a broad and complex gastrointestinal ecosystem. The use of a gnotobiotic animal model with a simplified intestinal microbial status allows the in vivo observation of interrelationships between microorganisms such as a probiotic and a pathogenic bacterium as well as between these microorganisms and the host.
Some experimental studies and/or clinical trials have been performed to confirm the efficacy of probiotics. Rodrigues et al. (8) and Silva et al. (9) have demonstrated protection against a challenge with Salmonella enterica subsp. enterica serovar Typhimurium when conventional and gnotobiotic mice were respectively inoculated with Saccharomyces boulardii or Bifidobacterium lactis. Similarly, the prophylactic treatment of gnotobiotic and conventional mice with the probiotics Lactobacillus delbrueckii H2B20 or S. boulardii, respectively, protects the animals against challenge with the same pathogen by immune mechanisms $(10,11)$. Likewise, several nonpathogenic Escherichia coli strains have also been used as probiotics. Duval-Iflah et al. (12) have achieved some success in reducing the number of antibiotic-resistant $E$. coli in infant feces by inoculating children just after birth with a plasmid-free human E. coli (EMO strain), which suppresses the multiplication of plasmid-bearing strains in the intestinal tract. Moreover, a commercial consortium of E. coli is believed to result in beneficial effects for premature infants (13). Other E. coli preparations, administered orally, have been used in adults as an option for maintenance therapy of ulcerative colitis (14) or immunomodulation $(13,15)$.

In the present study, we investigated the probiotic properties of the non-pathogenic, plasmid-free E. coli (EMO strain). This strain has been reported to increase the weight gain of piglets and decrease the frequency of diarrhea in newborn babies $(16,17)$. Thus, the aim of the present study was to assess whether $E$. coli EMO strain, alone, is capable of protecting gnotobiotic mice against an oral challenge with Salmonella Typhimurium by possible antagonistic and/or immune mechanisms.

\section{Material and Methods}

\section{Mice}

Adult germ-free 21-day-old Swiss/NIH 
mice (Taconic, Germantown, NY, USA) of both sexes were used in this study. The animals were housed in flexible plastic isolators (Standard Safety Company, Pallatine, IL, USA) and handled according to established procedures (18). Water and commercial autoclavable diet (Nuvital, Curitiba, PR, Brazil) were sterilized with steam and administered ad libitum. Experiments with gnotobiotic mice were carried out in microisolators (UNO Roestvaststaal, B.V., Zevenar, The Netherlands). The mice were maintained in an animal house with controlled lighting (12$\mathrm{h}$ light-dark cycles). All experimental procedures were carried out according to the standards set forth in the "Guide for the Care and Use of Laboratory Animals" of the National Research Council (19).

\section{Microorganisms}

The E. coli EMO strain was isolated from the intestines of a healthy human subject and identified at the Laboratoire d'Ecologie Microbienne (Dr. Y. Duval-Iflah, INRA, Jouy-en-Josas, France). Salmonella enterica subsp. enterica serovar Typhimurium was isolated from a human clinical case at Fundação Ezequiel Dias (FUNED, Belo Horizonte, MG, Brazil). E. coli B41 (0101:K99:F41) was a kind gift from Dr. H.W. Moon (National Association of Dental Laboratories, Ames, IA, USA). The bacteria were maintained at $-70^{\circ} \mathrm{C}$ in medium containing $20 \%$ glycerol. The identity of the bacteria was regularly confirmed by Gram staining and using the API 20E identification kit (BioMérieux, Marcy-L'Étoile, France).

\section{Treatments}

A single dose of E. coli EMO strain with approximately $10^{8}$ colony forming units (CFU) in $0.1 \mathrm{ml}$ PBS was inoculated intragastrically into germ-free mice (experimental groups) 10 days before challenge with Salmonella Typhimurium. The control groups were inoculated with $0.1 \mathrm{ml} \mathrm{PBS}, \mathrm{pH}$ 7.3 , according to the same schedule as the experimental group. Various experimental and control groups (5 to 10 mice per group according to the experiments) were used separately for determinations of survival, fecal population levels, intestinal sIgA levels, translocation, and blood clearance.

\section{Experimental infections}

Salmonella Typhimurium was grown in brain heart infusion (Difco) medium at $37^{\circ} \mathrm{C}$. After 10 days of monoassociation with $E$. coli EMO strain, each mouse was challenged orally with $0.1 \mathrm{ml}$ of the bacterial suspension containing $10^{2} \mathrm{CFU}$ pathogenic bacteria. Control groups were given the oral challenge with Salmonella Typhimurium at the same time as the experimental group. For the determination of survival, gnotobiotic mice were monitored until the 15 th day after challenge with Salmonella Typhimurium. For the other determinations (fecal population levels, intestinal IgA levels and translocation), experiments were carried out until the 6th day of infection.

\section{Fecal bacterial counts}

Feces from gnotobiotic mice were collected 1, 3 and 6 days after challenge with an anal stimulus and homogenized in PBS (1:100, w/v). Serial decimal dilutions were prepared and 0.1-ml aliquots were plated onto MacConkey agar (Difco). The Petri dishes were cultured at $37^{\circ} \mathrm{C}$ and colonies were counted after $24 \mathrm{~h}$.

\section{Translocation of Salmonella Typhimurium}

To measure translocation of Salmonella, gnotobiotic mice were sacrificed by ether inhalation 3 and 6 days after challenge. Then, mesenteric lymph nodes, liver and spleen were dissected, weighed and macerated in PBS (1:10 or $1: 100, w / v)$. Serial decimal 
dilutions were prepared and 0.1-ml aliquots were plated onto MacConkey agar (Difco). Counts were determined after incubation at $37^{\circ} \mathrm{C}$ for $24 \mathrm{~h}$.

\section{Histopathology}

Tissue samples from intestines and liver were fixed in 10\% formaldehyde in PBS and processed for paraffin embedding. The histopathological sections $(5 \mu \mathrm{m})$ were stained with hematoxylin-eosin. The slides were coded and examined by a single pathologist, who was unaware of the experimental conditions of each group.

\section{slgA determination in small bowel contents}

Total and anti-Salmonella Typhimurium sIgA in the small intestine of gnotobiotic mice was determined by ELISA 10 days after inoculation with E. coli EMO strain and 3 and 6 days after challenge with Salmonella Typhimurium. Mice were sacrificed by ether inhalation, the small intestine was removed, and the contents were withdrawn, weighed and suspended in PBS at $500 \mathrm{mg}$ of intestinal contents per $2.0 \mathrm{ml}$ PBS. After centrifuga-

Figure 1. Survival of Escherichia coli EMO strain in infected gnotobiotic mice orally challenged with Salmonella Typhimurium. Germ-free mice received PBS orally (control, open circles) or E. coli EMO strain (experimental, filled circles) 10 days before challenge. The figure illustrates one representative experiment of two, with similar results, using 6 mice per group and per experiment. ${ }^{*} P<0.05 \mathrm{com}-$ pared to control (Student $t$-test).

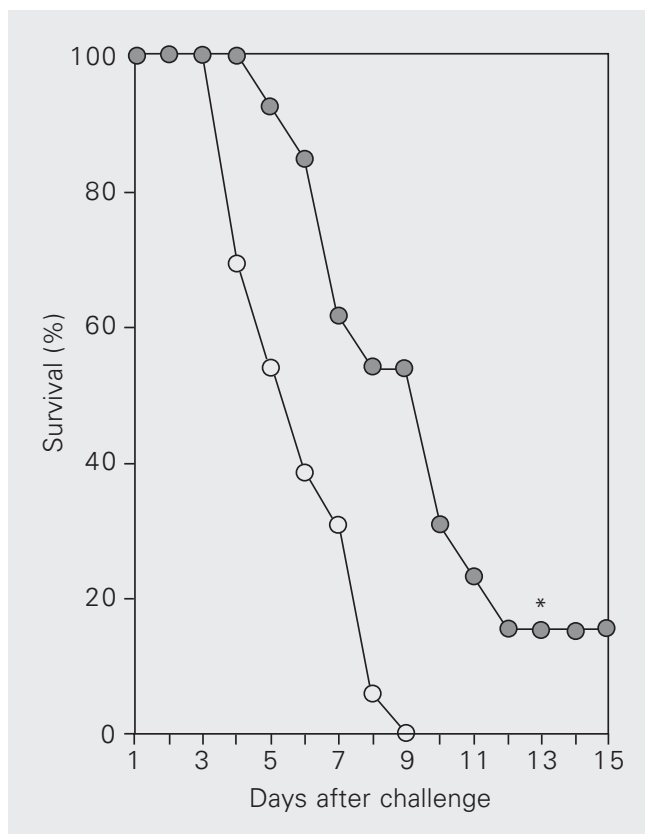

tion at $2000 \mathrm{~g}$ for $30 \mathrm{~min}$, the supernatant fluid was collected and kept frozen at $-70^{\circ} \mathrm{C}$ until use. The intestinal fluid samples were diluted 1:10 in PBS and serial dilutions were added in triplicate to the wells. Total SIgA in intestinal fluid was determined using goat anti-mouse IgA (M-8769, Sigma) and horseradish peroxidase-conjugated goat anti-mouse IgA (A-4789, Sigma). Color was developed with $o$-phenylenediamine (1,2-benzenediamine; Sigma) and absorbance at $492 \mathrm{~nm}$ was determined with an ELISA plate reader (ELISA READER 2550, Bio-Rad Laboratories). Anti-Salmonella Typhimurium sIgA was determined as described above except for the coating step. Briefly, the 96-well ELISA plates were coated with $0.1 \mathrm{ml}$ of a suspension containing $10^{8}$ heat-killed Salmonella Typhimurium $/ \mathrm{ml}$ coating buffer $(0.01$ $\mathrm{M}$ carbonate/bicarbonate, $\mathrm{pH}$ 9.6).

\section{Evaluation of bacterial blood clearance}

Bacterial blood clearance was tested as the capacity to clear a Gram-negative bacterium injected systemically in mice previously associated or not with E. coli EMO strain for 10 days. An 18-h culture of E. coli B41 was centrifuged at $2000 \mathrm{~g}$ and resuspended in sterile saline at $10^{8} \mathrm{CFU} / \mathrm{ml}$. This number of bacteria was estimated by turbidity $(\lambda=550$ $\mathrm{nm})$ and absorbance was adjusted to 0.3 of optical density. Mice were injected with 0.2 $\mathrm{ml}$ of the suspension into the tail vein after ether anesthesia. Blood samples were collected from the retro-orbital plexus of anesthetized animals immediately after injection (time 0) and at 30, 60 and $90 \mathrm{~min}$ after injection. After the last blood collection, mice were sacrificed. Ten-fold serial dilutions of blood samples were plated and cultured onto Petri dishes containing MacConkey agar (Difco). Dishes were incubated for $24 \mathrm{~h}$ at $37^{\circ} \mathrm{C}$ and colonies counted. Results are reported as percent $\mathrm{CFU}$ of the counts obtained at the initial time (time zero). Alternatively, $E$. coli B41 was pre-opsonized with serum 
from germ-free or E. coli EMO-monoassociated mice $(1: 10 / 1 \mathrm{~h})$ before intravenous challenge.

\section{Statistical analysis}

Data were analyzed statistically by the Fisher exact test and by the two-tailed Student $t$-test. The Epistat computer program (T.L. Gustafson, Round Rock, TX, USA) was used to carry out the tests and the level of significance was set at $\mathrm{P}<0.05$. All experiments were performed at least twice.

\section{Results}

Figure 1 shows that survival time after challenge with Salmonella Typhimurium was longer in gnotobiotic mice associated with $E$. coli EMO strain compared to control $(\mathrm{P}<$ 0.05). Moreover, histopathological examination confirmed the survival data since the mucosa of the colon of experimental animals showed less intense lesions such as edema, inflammatory cell infiltrate and hyperemia (Figure 2A,B). The epithelial cells of the mucosal surface and the mucous production were also better preserved in the experimental group. Besides, in livers of experimental animals, inflammatory foci were present only in some areas while the phenomenon was generalized in control mice (Figure 2C,D).

Figure 3 shows that the number of Salmonella Typhimurium in feces of experimental mice was decreased by about 10 -fold one day after challenge $(\mathrm{P}<0.05)$. However, no difference between experimental and control groups was observed 3 and 6 days after challenge. E. coli EMO strain reached and maintained high stable numbers in feces of gnotobiotic mice before and after challenge (about $10^{9} \mathrm{CFU} / \mathrm{g}$ of feces).

Figure 4 shows that the contents of $\operatorname{sIg} \mathrm{A}$ in the intestines of gnotobiotic mice 10 days after inoculation with $E$. coli EMO strain were higher compared to the germ-free group $(\mathrm{P}<0.05)$. The intestinal contents of anti-
Salmonella $\operatorname{sIg}$ A were also higher in the $E$. coli-monoassociated group before challenge with Salmonella Typhimurium $(\mathrm{P}<0.05)$. On the other hand, SIgA (total and antiSalmonella) were similar in both groups after challenge (Figure 4).

Figure 5 shows that translocation of Sal-
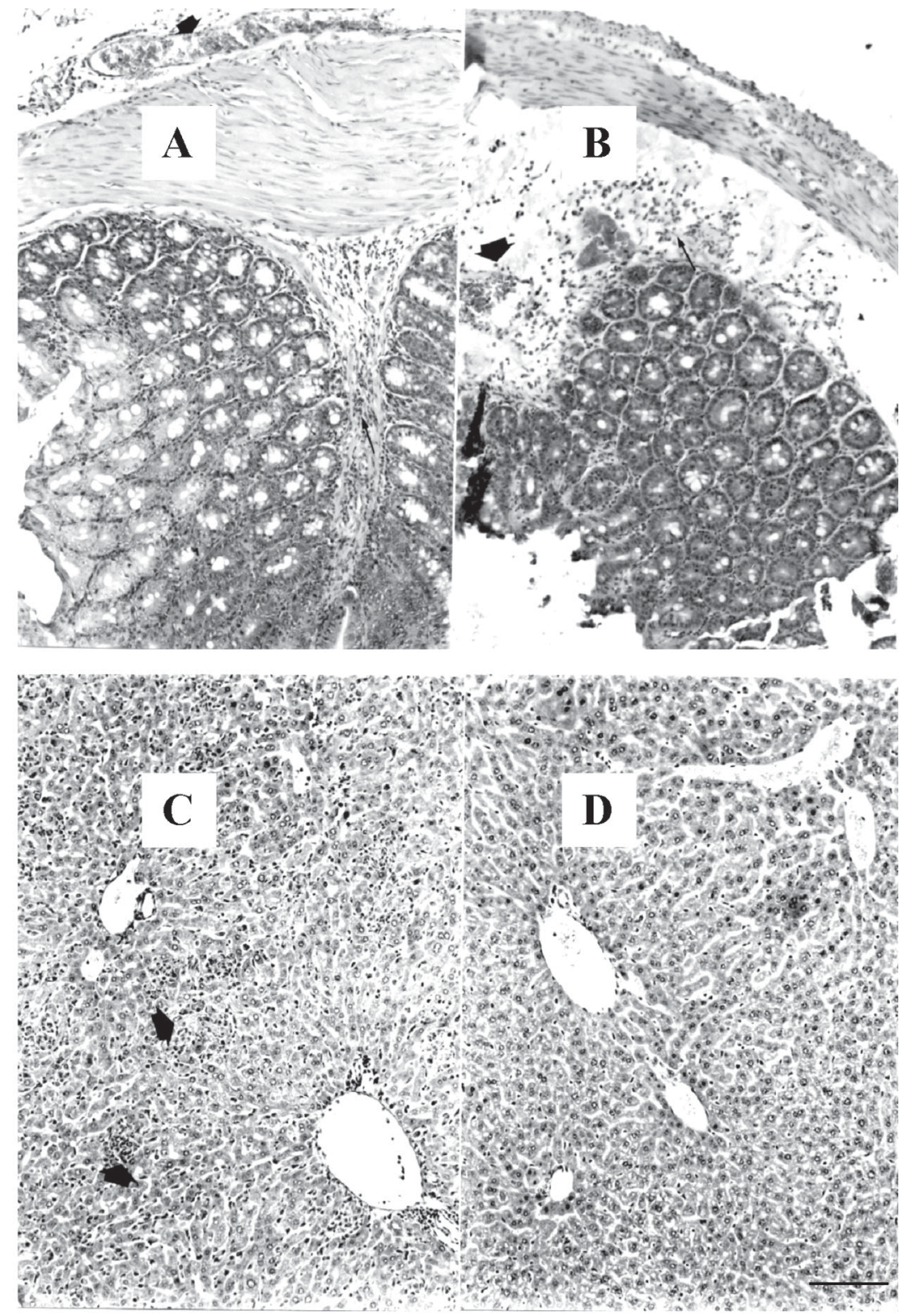

Figure 2. Histopathological aspects of the intestinal mucosa ( $A$ and $B$ ) and liver ( $C$ and $D)$ of gnotobiotic mice challenged with Salmonella Typhimurium. Germ-free mice received PBS orally (B and D) or Escherichia coli EMO strain ( $A$ and C) 10 days before challenge. Arrows indicate inflammatory foci. Hematoxylin-eosin. Original magnification, 64X. Bar $=$ $90.17 \mu \mathrm{m}$ 
Figure 3. Numbers of Salmonella Typhimurium in feces of control (open circles) and experimental (filled circles) gnotobiotic mice. Germ-free mice received PBS orally (control - 6 mice) or Escherichia coli EMO strain (experimental - 6 mice) 10 days before challenge. The figure represents one of two similar results. $\mathrm{CFU}=$ colony forming units. Means were compared by the Student $t$-test. ${ }^{*} P<0.05$ compared to control.

Figure 4. Total and anti-Salmonella Typhimurium slgA in the intestines of control and experimental gnotobiotic mice. Germfree mice received PBS (control) orally or Escherichia coli EMO strain (experimental) 10 days before challenge. Results were compared by the Student $t$-test. ${ }^{*} P<0.05$ compared to control. monella Typhimurium to the spleen was decreased 10-fold in experimental mice when compared with the germ-free group 3 days after challenge. However, this difference in translocation to the spleen was not observed after 6 days (Figure 5). No difference in translocation to the mesenteric lymph nodes or to livers was found at 3 and 6 days after challenge.

Clearance of E. coli B41 from the blood
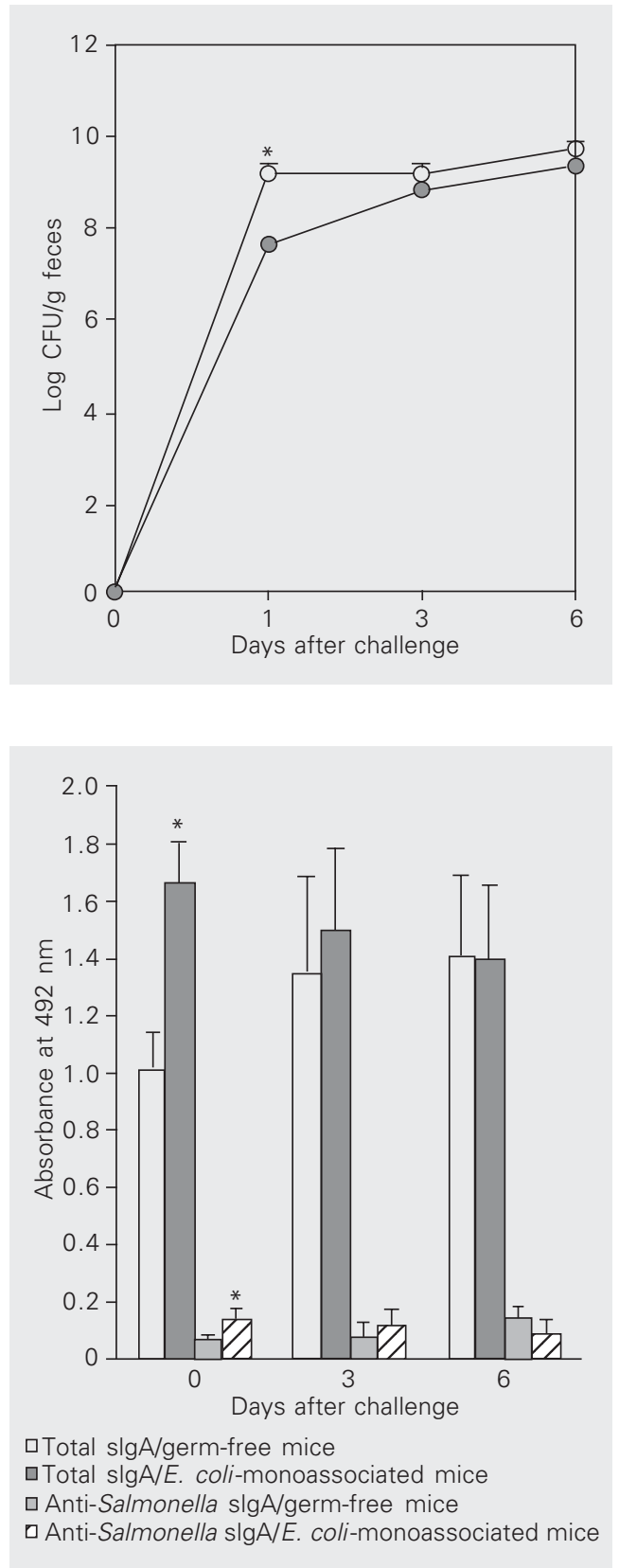

of gnotobiotic mice was similar in both experimental and control groups. Likewise, no difference in clearance was observed after pre-opsonization of E. coli B41 (data not shown).

\section{Discussion}

Evaluation of the mortality of gnotobiotic mice previously associated with $E$. coli $\mathrm{EMO}$ strain and challenged with Salmonella Typhimurium showed that $E$. coli was unable, by itself, to confer complete protection against the pathogen (Figure 1). However, in two of three experiments performed, a longer survival time and a higher survival frequency were observed for the experimental mice when compared to control animals. Additionally, the histopathological examination showed less intensive lesions in the intestines and liver of gnotobiotic mice associated with E. coli EMO strain after the pathogenic challenge (Figure 2).

In order to better understand the mechanisms involved in the observed protective effect, we first determined if the E. coli EMO strain antagonized Salmonella Typhimurium in vivo. The high counts of Salmonella Typhimurium in the feces of both groups showed that E. coli EMO strain did not inhibit the installation and growth of the pathogen in the intestines of gnotobiotic mice. However, a smaller number of Salmonella Typhimurium CFU were found in the experimental groups three days after infection, which may indicate that the E. coli EMO strain delayed the colonization of the digestive tract by Salmonella Typhimurium. Antagonism against a bacterial strain can vary independently of the sensitivity of the target strain. Hudault et al. (20) have shown that some strains of Clostridium perfringens can be inhibited by a combination of bacterial strains whereas others cannot. In a previous study, we have demonstrated the reduction of colonization of the intestines by a streptomycin-resistant strain of Shigella flexneri to 
undetectable numbers, as a result of monoassociation with $E$. coli EMO strain (21). However, the same kind of antagonism was not observed when mice were tri-associated with EMO and two other microorganisms and subsequently challenged with Salmonella Typhimurium (21). Moreover, we have found in ex vivo experiments that a small inhibition zone around the feces of E. colimonoassociated mice is formed against Salmonella flexneri, but not against Salmonella Typhimurium (data not shown). In fact, Hudault et al. (22) have recently reinforced our findings that the $E$. coli EMO strain does not produce microcins against Salmonella Typhimurium. Moreover, they have shown that $E$. coli EMO strain does not compete with Salmonella Typhimurium for adhesion sites in an enterocyte cell culture.

To assess if a humoral immune response could be related to the protective effect observed in the early phase of infection with Salmonella Typhimurium in gnotobiotic mice, we determined IgA concentrations in the intestinal contents. E. coli EMO strain enhanced the local production of $\operatorname{sIg} \mathrm{A}$ in the intestines of monoassociated mice. This enhancement was partly due to the production of sIgA specific for the EMO strain of E. coli (data not shown). We also observed higher amounts of sIgA that bound to Salmonella Typhimurium in the intestinal contents from monoassociated mice. These immunoglobulins could be induced by E. coli EMO strain and may be cross-reactive with cells of Salmonella Typhimurium (Figure 4). Perhaps the presence of Salmonella Typhimurium-binding sIgA could explain the decreased numbers of Salmonella Typhimurium cells found in feces from experimental animals soon after the challenge. The main role of sIgA during gut infections is to mediate the neutralization of bacterial invasiveness and toxins, thus preventing translocation to internal organs. An increased production of $\operatorname{IgA}$ has been particularly demonstrated after association of mice with selected lactic acid bacteria. Enhancement of the amount of IgA-producing plasma cells by Lactobacillus casei or L. acidophilus has been reported (23). In addition, Tejada-Simon et al. (24) showed increased IgA production in response to cholera toxin in mice treated with a yogurt containing a mixture of L. acidophilus and Bifidobacterium spp. On the other hand, studies associating the administration of non-pathogenic $E$. coli with the induction of antibody responses are rare and the results sometimes controversial. Lodinová-Zádniková et al. (13) and Jansen et al. (15) have shown that two commercial associations of E. coli, Mutaflor and Symbioflor, respectively, cause an increase in titers of specific anti-E. coli immunoglobulins. Therefore, the former authors argue that cross-reactive interactions can be triggered by the administration of the consortium producing some protection against enteropathogens. In fact, our results showed that IgA cross-reacting against a non-related species can be induced. However, after challenge with Salmonella Typhimurium, sIgA was present in the intestinal contents at similar levels in both experimental and control groups.

To investigate if the monoassociation of gnotobiotic mice with the E. coli EMO strain could trigger a systemic response, thus promoting killing of Salmonella Typhimurium,

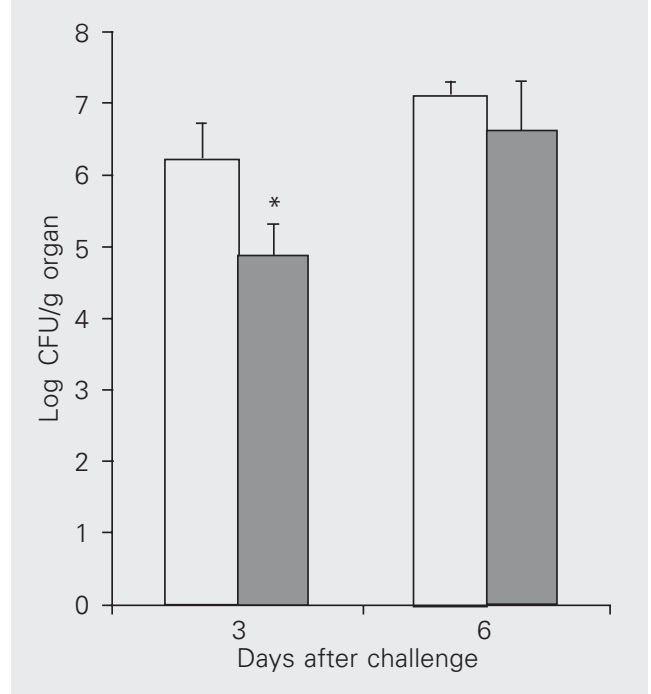

Figure 5. Translocation of Salmonella Typhimurium to the spleens of control (open columns) and experimental (filled columns) gnotobiotic mice. Germ-free mice received PBS (control) orally or Escherichia coli EMO strain (experimental) 10 days before challenge. The figure represents one of two similar results. Three mice were used per group on each day. $\mathrm{CFU}=$ colony forming units . Mean population numbers of Salmonella Typhimurium were compared by the Student $t$-test. ${ }^{*} \mathrm{P}<0.05$ compared to control. 
the translocation of the pathogen to the mesenteric lymph nodes, liver and spleen was determined. The translocation of Salmonella Typhimurium was only decreased in the spleen of E. coli EMO-monoassociated mice 3 days after the challenge, suggesting that $E$. coli could enhance the activity of macrophages only in the early phase of infection (Figure 5). The spleen contains large numbers of macrophages, dendritic cells and $\mathrm{B}$ and $\mathrm{T}$ lymphocytes, and works as a filter for microorganisms and antigens circulating in the blood. The macrophages from the red pulp are responsible for phagocytosis, especially of antibody-coated microbes (opsonized). In previous studies $(10,25)$, stimulation of the phagocytic capacity of the host macrophages was obtained using treatments with different Lactobacillus strains. To determine if the clearance capacity of monoassociated mice was altered, a pathogenic strain of $E$. coli $\mathrm{B} 41$ was injected intravenously and the number of bacteria in the bloodstream was determined at several times. Since phagocytoses by macrophages and dendritic cells are theoretically increased by opsonization of bacteria in the blood we also pre-opsonized the pathogenic strain of $E$. coli $\mathrm{B} 41$ with serum from germ-free or E. coli-monoassociated mice before the intravenous challenge. Monoassociation with the E. coli EMO strain did not increase the clearance capacity of mice.

During the course of the present study, we became aware of the report by Hudault et al. (22) which showed a high protection of animals previously treated with the EMO strain against Salmonella Typhimurium strain C5. Here, we report that E. coli EMO strain promoted only a limited protection in gnotobiotic mice challenged with the pathogen, as shown by the mortality rates and by histopathological examination. The protection observed here was not related to the reduction of the pathogenic populations in the intestines. The discrepancy between the two reports could be explained by differences in the animal model and the strain of Salmonella typhimurium used in the studies. In addition, we found that $E$. coli EMO strain enhances a local humoral immune response in the intestines of gnotobiotic mice, represented by sIgA production that can potentially influence the course of the pathogenesis caused by oral challenge with Salmonella Typhimurium or other Gram-negative pathogens in the murine model. There was no evidence of the involvement of the endothelial reticulum system in the protective effect observed. However, the involvement of NK or CTL cells cannot be ruled out.

We conclude that association with E. coli EMO strain conferred partial protection against Salmonella Typhimurium and that this partial protection may be mediated by induction of $\operatorname{sIg} \mathrm{A}$ production in the gut.

\section{Acknowledgments}

The authors are grateful to Maria Gorete Barbosa Ribas for valuable technical help, and to Ronilda Maria de Paula (in memoriam), Maria Helena Alves de Oliveira and Antônio Mesquita Vaz for animal care.

\section{References}

1. WHO (1994). Scientific Working Group on Monitoring and Management of Bacterial Resistance to Antimicrobial Agents. WHO, Geneva, Switzerland.

2. Fuller R (1992). Probiotics: the Scientific Basis. Chapman \& Hall, London, UK.

3. Vandenbergh PA (1993). Lactic acid bacteria, their metabolic products and interference with microbial growth. FEMS Microbiology
Reviews, 12: 221-238.

4. Bernet MF, Brassart D, Neeser JR \& Servin AL (1994). Lactobacillus acidophilus LA1 binds to human intestinal cell lines and inhibits cell attachment and cell invasion by enterovirulent bacteria. Gut, 35: 483-489.

5. Czerucka D, Roux I \& Rampal P (1994). Saccharomyces boulardii inhibits secretaguoge-mediated adenosine $3^{\prime}, 5^{\prime}$-cyclic mono- 
phosphate induction in intestinal cells. Gastroenterology, 106: 6572.

6. Brandão RL, Castro IM, Bambirra EA, Amaral SC, Fietto LG, Tropia MJM, Neves MJ, Santos RG, Gomes NCM \& Nicoli JR (1998). Intracellular signal triggered by cholera toxin in Saccharomyces boulardii and Saccharomyces cerevisiae. Applied and Environmental Microbiology, 64: 564-568.

7. Machado Caetano JA, Parames MT, Babo MJ, Santos A, Bandeira Ferreira A, Freitas AA, Clemente Coelho MR \& Mateus AM (1986). Immunopharmacological effects of Saccharomyces boulardii in healthy volunteers. International Journal of Immunopharmacology, 8: 245-249.

8. Rodrigues ACP, Nardi RM, Bambirra EA, Vieira EC \& Nicoli JR (1996). Effect of Saccharomyces boulardii against experimental oral infection with Salmonella typhimurium and Shigella flexneri in conventional and gnotobiotic mice. Journal of Applied Bacteriology, 81: 251-256.

9. Silva AM, Bambirra EA, Oliveira AL, Souza PP, Gomes DA, Vieira EC \& Nicoli JR (1999). Protective effect of bifidus milk on the experimental infection with Salmonella enteritidis subsp. typhimurium in conventional and gnotobiotic mice. Journal of Applied Microbiology, 86: 331-336.

10. Neumann E, Oliveira MAP, Cabral CM, Moura LN, Nicoli JR, Vieira EC, Cara DC, Podoprigora GI \& Vieira LQ (1998). Monoassociation with Lactobacillus acidophilus H2B20 stimulates the immune defense mechanisms of germfree mice. Brazilian Journal of Medical and Biological Research, 31: 1565-1573.

11. Rodrigues ACP, Cara DC, Fretez SHGG, Cunha FQ, Vieira EC, Nicoli JR \& Vieira LQ (2000). Saccharomyces boulardii stimulates $\operatorname{sgA}$ production and the phagocytic system of gnotobiotic mice. Journal of Applied Microbiology, 89: 404-414.

12. Duval-Iflah Y, Ouriet MF, Moreau C, Daniel N, Gabilan JC \& Raibaud P (1982). Implantation précoce d'une souche de Escherichia coli dans l'intestin du nouveau-né humain: effet de barrière vis-à-vis de souches de E. coli antibiorésistantes. Annales de Microbiologie (Institut Pasteur), 133A: 393-408

13. Lodinová-Zádniková R, Tlaskalova-Hogenová H \& Sonnenborn U (1996). Local and serum antibody response in full-term and premature infants after artificial colonization of the digestive intestine with Escherichia coli strain Nissle 1917 (Mutaflor). Pediatric Allergy and Immunology, 62: 4608-4613.

14. Kruiz W, Schutz E, Fric P, Fixa B, Judmaier G \& Stolte M (1997). Double-bind comparison of an oral Escherichia coli preparation and mesalazine in maintaining remission of ulcerative colitis. Alimentary Pharmacology and Therapeutics, 11: 853-858.

15. Jansen GJ, Wildeboer-Veloo AC, van de Waaij D \& Degener JE (1998). Escherichia coli as a probiotic? Infection, 26: 232-233.

16. Araujo PCR, Nardi RD, Martins C, Raibaud P, Duval-Iflah Y \& Nicoli JR (1996). Use of an Escherichia coli as probiotic for piglets. Microecology and Therapy, 24: 317-320.

17. Figueiredo PP, Vieira EC, Nicoli JR, Nardi RD, Raibaud P, Duval-Iflah Y \& Penna FJ (2001). Influence of oral inoculation with Escherichia coli EMO on the frequency of diarrhea during the first year of life in human newborns. Journal of Pediatric Gastroenterology and Nutrition, 33: 70-74.

18. Pleasants JR (1974). Gnotobiotics. In: Melby EC \& Altman NH (Editors), Handbook of Laboratory Animal Science. CRC Press, Cleveland, $\mathrm{OH}$, USA.

19. National Research Council (1996). Guide for the Care and Use of Laboratory Animals. National Academy Press, Washington, DC, USA.

20. Hudault S, Raibaud P, Ducluzeau R \& Bridonneau C (1982). Effet antagoniste à l'égard de Clostridium perfringens exercé par des souches de Clostridium isolées de la microflore de souris holoxêniques dans le tube digestif de souris gnotoxêniques. Annales de Microbiologie (Institut Pasteur), 133A: 443-459.

21. Lima Filho JVM, Vieira EC \& Nicoli JR (2000). Antagonistic effect of Lactobacillus acidophilus, Saccharomyces boulardii and Escherichia coli combinations against experimental infections with Shigella flexneri and Salmonella enteritidis subsp. typhimurium. Journal of Applied Microbiology, 88: 365-370.

22. Hudault S, Guignot J \& Servin AL (2001). Escherichia coli strains colonising the gastrointestinal tract protect germ-free mice against Salmonella typhimurium infection. Gut, 49: 47-55.

23. Perdigon G, Alvarez S, Rachid M, Aguero G \& Gobbato N (1995). Immune system stimulation by probiotics. Journal of Dairy Science, 78: 1597-1606.

24. Tejada-Simon MV, Lee JH, Ustunol Z \& Pestka JJ (1999). Ingestion of yogurt containing Lactobacillus acidophilus and Bifidobacterium to potentiate immunoglobulin $A$ responses to cholera toxin in mice. Journal of Dairy Science, 82: 649-660.

25. Perdigon G, Nader de Macias ME, Alvarez S, Oliver G \& Ruiz Holgado AAP (1986). Effect of perorally administered lactobacilli on macrophage activation in mice. Infection and Immunity, 53: 404410. 